\title{
Extension of Operation of Space Vector PWM Strategies With Low Switching Frequencies Using Different Overmodulation Algorithms
}

\author{
G. Narayanan, Member, IEEE, and V. T. Ranganathan, Senior Member, IEEE
}

\begin{abstract}
This paper investigates the operation of four space vector-based synchronized pulse-width modulation (PWM) strategies in the overmodulation zone using three different overmodulation algorithms. It is shown that the symmetries in the PWM waveforms generated can be preserved in the overmodulation zone also. With any given overmodulation algorithm, the voltage control characteristics (i.e., fundamental voltage versus control variable) are found to vary with PWM strategy, pulse number and type of clamping. The inverse of the appropriate voltage control curve is used during premodulation to maintain the modulator gain constant. The differences in the nature of the voltage control characteristics with the different overmodulation algorithms are brought out. These characteristics are compared and contrasted against those at high switching frequencies. The harmonic distortion in the different cases is evaluated and compared. It is shown that the bus clamping strategies perform better than the conventional strategy with any given overmodulation algorithm employed. These strategies, which exploit the flexibilities in the space vector approach, are useful in high power drives on account of their superior waveform quality at low switching frequencies and high de bus utilization.
\end{abstract}

Index Terms-Harmonic distortion, induction motor drives, inverters, overmodulation, pulse-width modulation, space vector, vectors, voltage control.

\section{INTRODUCTION}

$\mathbf{O}$ VERMODULATION in pulse-width modulation (PWM) voltage source inverters (VSI) has been widely discussed in the literature [1]-[8]. Different overmodulation algorithms have been proposed for continuous control of space vector modulated inverters up to the six-step mode [5]-[8]. Bolognani et al. consider the whole overmodulation zone as a single undivided zone [5]. In the two-zone algorithm, the overmodulation zone is divided into overmodulation zone-I and overmodulation zone-II, and different procedures are adopted in the two zones [6], [7]. The modified two-zone algorithm also adopts a two-zone approach to overmodulation, but uses control variables and calculations that are different from those of the two-zone algorithm [8].

The space vector approach to PWM offers additional flexibilities like division of active state time, double switching of a phase within a subcycle, clamping of two phases within a subcycle etc. over the classical triangle-comparison approach [8]-[10]. These flexibilities have been exploited recently in the

\footnotetext{
Manuscript received June 4, 2001; revised April 30, 2002. Recommended by Associate Editor G. K. Dubey.

The authors are with the Department of Electrical Engineering, Indian Institute of Science, Bangalore 560 012, India (e-mail: vtran@ee.iisc.ernet.in).
} Publisher Item Identifier 10.1109/TPEL.2002.802190.

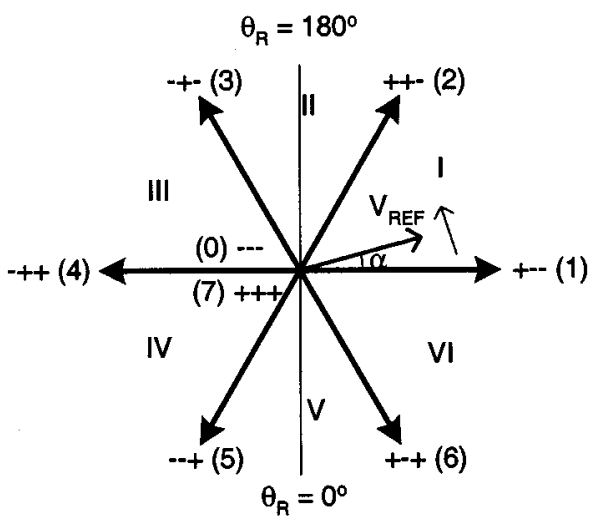

Fig. 1. Voltage vectors produced by a three-phase voltage source inverter. I-VI are sectors.

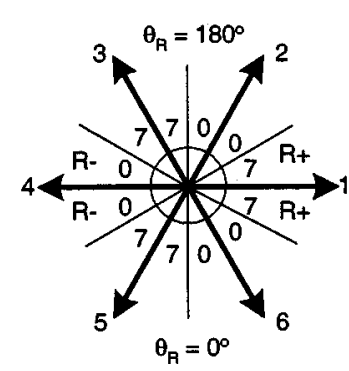

(a)

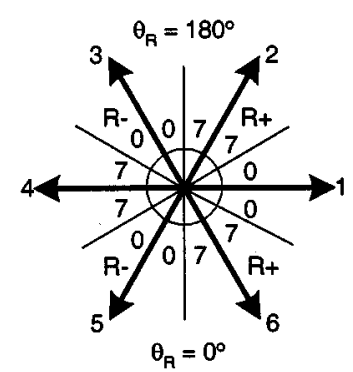

(b)
Fig. 2. Types of bus clamping: (a) $60^{\circ}$ clamping—every phase clamped during the middle $60^{\circ}$ duration of every half cycle of its fundamental voltage and (b) $30^{\circ}$ clamping - every phase clamped during the middle $30^{\circ}$ duration of every quarter cycle of its fundamental voltage.

design of synchronized PWM strategies for high power drives with low switching frequencies [8]-[10]. These strategies result in lesser harmonic distortion over comparable strategies at medium and high speeds in high power drives [8], [11].

Apart from low harmonic distortion subject to low switching frequencies, the PWM techniques for high power drives must also desirably ensure a high dc bus utilization [12]. In other words, the PWM techniques must desirably operate up to the six-step mode.

The overmodulation algorithms in the literature are essentially meant for high switching frequency space vector modulated inverters. This paper investigates the application of these algorithms to the above low switching frequency space vectorbased synchronized PWM strategies to extend the range of operation of the latter. 
TABLE I

SpaCE VeCtor-BASEd SyNCHRONIZED PWM StRATEGIES

\begin{tabular}{|c|c|c|c|c|c|}
\hline Strategy & $\begin{array}{l}\text { Samples per } \\
\text { sector }(\mathrm{N})\end{array}$ & Positions of samples $(\alpha)$ & Sequences used in sector I & $\begin{array}{l}\text { Nominal pulse } \\
\text { number }\left(\mathrm{P}_{\mathrm{NOM}}\right)\end{array}$ & $\begin{array}{l}\text { Type of } \\
\text { clamping }\end{array}$ \\
\hline CSVS & 3 & $10^{\circ}, 30^{\circ}, 50^{\circ}$ & $7210,0127,7210$ & 9 & - \\
\hline CSVS & 5 & $6^{\circ}, 18^{\circ}, 30^{\circ}, 42^{\circ}, 54^{\circ}$ & $0127,7210,0127,7210,0127$ & 15 & - \\
\hline CSVS & 7 & $\begin{array}{c}4.3^{\circ}, 12.9^{\circ}, 21.4^{\circ}, 30^{\circ}, 38.6^{\circ} \\
47.1^{\circ}, 55.7^{\circ}\end{array}$ & $\begin{array}{c}7210,0127,7210,0127,7210 \\
0127,7210 \\
\end{array}$ & 21 & - \\
\hline BBCS & 3 & $10^{\circ}, 30^{\circ}, 50^{\circ}$ & $127,7210,012$ & 7 & $60^{\circ}$ \\
\hline BBCS & 5 & $6^{\circ}, 18^{\circ}, 30^{\circ}, 42^{\circ}, 54^{\circ}$ & $721,127,7210,012,210$ & 11 & $60^{\circ}$ \\
\hline BBCS & 5 & $6^{\circ}, 18^{\circ}, 30^{\circ}, 42^{\circ}, 54^{\circ}$ & $012,210,0127,721,127$ & 11 & $30^{\circ}$ \\
\hline BBCS & 7 & $\begin{array}{c}4.3^{\circ}, 12.9^{\circ}, 21.4^{\circ}, 30^{\circ}, 38.6^{\circ} \\
47.1^{\circ}, 55.7^{\circ}\end{array}$ & $127,721,127,7210,012,210,012$ & 15 & $60^{\circ}$ \\
\hline BSS & 2 & $0^{\circ}, 30^{\circ}$ & 010,0127 & 5 & $30^{\circ}$ \\
\hline BSS & 4 & $0^{\circ}, 15^{\circ}, 30^{\circ}, 45^{\circ}$ & $101,127,7210,012$ & 9 & $60^{\circ} *$ \\
\hline BSS & 6 & $0^{\circ}, 10^{\circ}, 20^{\circ}, 30^{\circ}, 40^{\circ}, 50^{\circ}$ & $010,012,210,0127,721,127$ & 13 & $30^{\circ}$ \\
\hline AZCS & 2 & $15^{\circ}, 45^{\circ}$ & 7212,210 & 5 & $60^{\circ}$ \\
\hline AZCS & 2 & $15^{\circ}, 45^{\circ}$ & 0121,127 & 5 & $30^{\circ}$ \\
\hline AZCS & 4 & $7.5^{\circ}, 22.5^{\circ}, 37.5^{\circ}, 52.5^{\circ}$ & $127,7212,210,012$ & 9 & $60^{\circ}$ \\
\hline AZCS & 6 & $5^{\circ}, 15^{\circ}, 25^{\circ}, 35^{\circ}, 45^{\circ}, 55^{\circ}$ & $721,127,7212,210,012,210$ & 13 & $60^{\circ}$ \\
\hline AZCS & 6 & $5^{\circ}, 15^{\circ}, 25^{\circ}, 35^{\circ}, 45^{\circ}, 55^{\circ}$ & $012,210,0121,127,721,127$ & 13 & $30^{\circ}$ \\
\hline
\end{tabular}

* with a small discontinuity in the middle of the clamping duration

Four space vector-based synchronized PWM strategies are described briefly in Section II. In Section III, the three overmodulation algorithms are explained, and their application to the synchronized PWM strategies is investigated. The results and conclusions are presented in Sections IV and V, respectively.

\section{SPACE VECTOR-BASED SyNCHRONIZED PWM STRATEGIES}

The voltage vectors produced by an inverter are shown in Fig. 1. In the space vector approach to PWM, given a sample of the reference vector with magnitude $V_{\mathrm{REF}}$ and angle $\alpha$ as shown in Fig. 1, the active state $\mathbf{1}$, the active state $\mathbf{2}$, and the two zero states together are applied for durations $T_{1}, T_{2}$ and $T_{Z}$, respectively, within the given subcycle $T_{S}$ as given in (1) [8]-[10], [13]-[17]

$$
\begin{aligned}
T_{1} & =T_{S}{ }^{*} V_{\mathrm{REF}} \frac{{ }^{*} \sin \left(60^{\circ}-\alpha\right)}{\sin \left(60^{\circ}\right)} ; \\
T_{2} & =T_{S}{ }^{*} V_{\mathrm{REF}} \frac{{ }^{*} \sin (\alpha)}{\sin \left(60^{\circ}\right)} \\
T_{Z} & =T_{S}-T_{1}-T_{2} .
\end{aligned}
$$

The apportioning of $T_{Z}$ between the two zero states $\mathbf{0}$ and $\mathbf{7}$ in the space vector approach is equivalent to the addition of triplen frequency components in the classical triangle-comparison approach [8], [9], [15]-[17]. Exploitation of this equivalence can make PWM generation simpler [18], [19]. Apart from division of $T_{Z}$, division of active state time is also possible with the space vector approach. For example, sequence 0121, 1210, 7212, or 2127, with either $T_{1}$ or $T_{2}$ divided into two equal halves, can also be used to generate the commanded average vector instead of sequence $\mathbf{0 1 2 7}$ or 7210. This has no equivalence in the triangle-comparison approach [8]-[10].
At low switching frequencies, the PWM waveform generated must be synchronized with its own fundamental component and must also possess waveform symmetries for good spectral properties. The conditions for maintaining the waveform symmetries have been brought out. It has been shown that synchronized PWM waveforms with symmetries can be defined in terms of

i) number of samples per sector $(N)$;

ii) positions of samples in every sector;

iii) switching sequences used for every sample in a given sector [8], [10].

In conventional space vector strategy (CSVS) and basic bus clamping strategy (BBCS), $N$ is odd as shown in Table I. But, $N$ is even in boundary sampling strategy (BSS) and asymmetric zero-changing strategy (AZCS). The samples are positioned symmetrically about the centre of every sector (i.e., $\alpha=30^{\circ}$ ) in all the strategies. There is a sample at $\alpha=30^{\circ}$ in all strategies except AZCS. In CSVS, both the zero states are used for every sample. The bus clamping strategies use one zero state in the first half and the other zero state in the second half of the sector as shown in the table. The choice of zero state used leads to $60^{\circ}$ clamping or $30^{\circ}$ clamping, illustrated in Fig. 2(a) and (b), respectively. In BBCS and BSS, the zero state used is changed in the middle of the sector using sequence $\mathbf{0 1 2 7}$ or $\mathbf{7 2 1 0}$ for the sample at $\alpha=30^{\circ}$. In AZCS, the zero state is changed over the middle two subcycles using sequences 0121,127 or 7212, 210. There is a sample at $\alpha=0^{\circ}$ only in BSS. Sequence $\mathbf{0 1 0}$ or 101, with either $T_{Z}$ or $T_{1}$ divided into two equal halves, is used to generate this sample as shown in the table [8], [10].

The nominal pulse number $\left(P_{\mathrm{NOM}}\right)$ is defined as the ratio of switching frequency $\left(F_{\mathrm{SW}}\right)$ to the fundamental frequency $\left(F_{1}\right)$ in the linear modulation zone or before the onset of pulse dropping. $P_{\mathrm{NOM}}=3 N$ for CSVS, and $P_{\mathrm{NOM}}=(2 N+1)$ for the bus clamping strategies (see Table I). 


\section{OVERMODULATION}

In the present work, modulation index $(M)$ is defined as the ratio of the fundamental voltage generated to the fundamental voltage corresponding to six-step operation with the given DC bus voltage. At fairly high switching frequencies, $M$ and $V_{\mathrm{REF}}$ are proportional in the linear modulation zone (up to $V_{\mathrm{REF}}=$ 0.866 or $M=0.907$ ) as given by

$$
M=\left(\frac{0.907}{0.866}\right) * V_{\mathrm{REF}} .
$$

This paper investigates the extension of operation of the synchronized PWM strategies up to $M=1$, preserving the waveform symmetries and maintaining the modulator gain constant throughout.

\section{A. Two Approaches to Overmodulation}

In the linear modulation zone, the tip of the average vector generated has a circular trajectory of radius $V_{\mathrm{CIR}}$ during steady state as shown in Fig. 3(a). When $V_{\mathrm{CIR}}$ is between 0.866 and 1.0, the circle is partly outside and partly within the hexagon, formed by the tips of the six active vectors. The inverter cannot generate an average vector, whose tip falls outside the hexagon. The circle intersects the hexagon at an angle $\alpha_{\mathrm{INT}}$, measured from the sector boundaries as shown in Fig. 3(b). If all the average vectors generated are confined to the spatial regions where the circle is within the hexagon as shown in Fig. 3(b), then as $V_{\mathrm{CIR}}$ increases toward 1 (or as $\alpha_{\mathrm{INT}}$ decreases toward $0^{\circ}$ ), the operation tends to the six-step mode. This is the one-zone approach to overmodulation. The one-zone algorithm follows such an approach [5].

Alternatively, $M$ is first increased by increasing the lengths of the average vectors generated till their tips touch the hexagon in overmodulation zone-I [see Fig. 4(a)]. $M$ is further increased by shifting the average vectors closer to the nearest sector boundary with their tips touching the hexagon in overmodulation zone-II [see Fig. 4(b)]. The trajectory of the tip of the average vector generated is partly circular and partly hexagonal in zone-I, and is fully hexagonal in zone-II as shown in Fig. 4(a) and (b), respectively. This is the two-zone approach to overmodulation, followed by the two-zone algorithm [6], [7] and the modified two-zone algorithm [8].

Different algorithms use different quantities termed as 'control variables' in different zones of modulation to control the fundamental voltage or $M$. The control variables used by the above overmodulation algorithms are listed in Table II.

\section{B. Premodulation}

During overmodulation, the sampled reference vector must first be corrected suitably before calculation of inverter state times in every subcycle as shown in Fig. 5. Such a correction or transformation is termed as "premodulation" [5]-[8]. In premodulation, the value of the control variable corresponding to given $V_{\mathrm{REF}}$ is first determined. The magnitude $\left(V_{P}\right)$ and the angle $\left(\alpha_{P}\right)$ of the premodulated sample are then calculated using the control variable and $\alpha$. Equations used by one-zone, two-zone and modified two-zone algorithms to calculate $V_{P}$ and $\alpha_{P}$ are given in Table III. $V_{P}$ and $\alpha_{P}$ are then used (instead

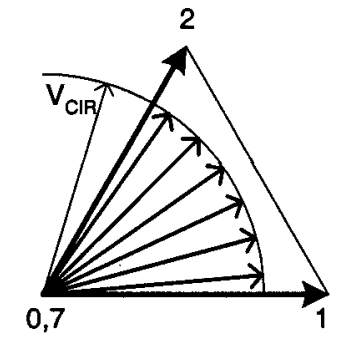

(a)

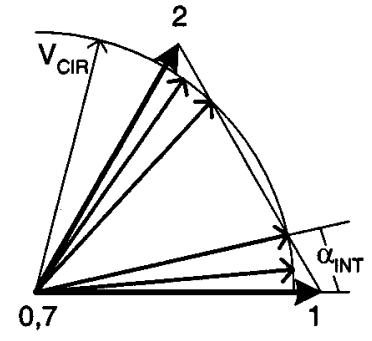

(b)
Fig. 3. One-zone approach to overmodulation. (a) Linear modulation zone and (b) overmodulation zone. $V_{\mathrm{CIR}}$ : Radius of circular trajectory; $\alpha_{\mathrm{INT}}$ : angle of intersection.

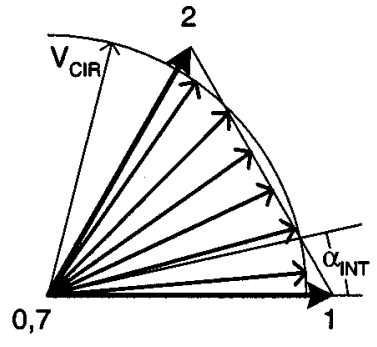

(a)

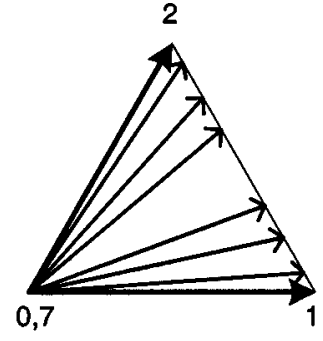

(b)
Fig. 4. Two-zone approach to overmodulation. (a) Overmodulation zone-I and (b) overmodulation zone-II.

TABLE II

CONTROL VARIABLES

\begin{tabular}{|c|c|c|}
\hline $\begin{array}{l}\text { Overmodulation } \\
\text { algorithm }\end{array}$ & $\begin{array}{c}\text { Zone of } \\
\text { modulation }\end{array}$ & Control variable \\
\hline $\begin{array}{c}\text { 1-zone } \\
\text { algorithm }\end{array}$ & $\begin{array}{c}\text { Overmodulation } \\
\text { zone } \\
\end{array}$ & $\begin{array}{l}\text { Radius of circular } \\
\text { trajectory } V_{C I R}[5]\end{array}$ \\
\hline \multirow{2}{*}{$\begin{array}{l}\text { 2-zone } \\
\text { algorithm }\end{array}$} & $\begin{array}{c}\text { Overmodulation } \\
\text { zone-I }\end{array}$ & $\begin{array}{c}\text { Angle of } \\
\text { intersection } \alpha_{\mathrm{INT}}[7\end{array}$ \\
\hline & $\begin{array}{c}\text { Overmodulation } \\
\text { zone-II }\end{array}$ & Hold angle \\
\hline \multirow{2}{*}{$\begin{array}{c}\text { Modified 2-zone } \\
\text { algorithm }\end{array}$} & $\begin{array}{c}\text { Overmodulation } \\
\text { zone-I }\end{array}$ & $\begin{array}{l}\text { Radius of circular } \\
\text { trajectory } V_{C I R}[8]\end{array}$ \\
\hline & $\begin{array}{c}\text { Overmodulation } \\
\text { zone-II } \\
\end{array}$ & $\begin{array}{l}\text { Angle correction } \\
\text { factor } \mathrm{K}_{\mathrm{ANG}}[8]\end{array}$ \\
\hline
\end{tabular}

of $V_{\mathrm{REF}}$ and $\alpha$ ) to calculate the inverter state times, and thereby, the switching instants of the three phases as shown in Fig. 5.

\section{One-Zone Overmodulation Algorithm}

With one-zone algorithm, the overmodulation zone starts at $V_{\mathrm{CIR}}=0.866$ in case of CSVS, BBCS, and BSS, which have a sample at $\alpha=30^{\circ}$ (see Table I). In case of AZCS, which has no sample at $\alpha=30^{\circ}$, it starts at $V_{\mathrm{CIR}}=0.866 / \cos \left(30^{\circ} / \mathrm{N}\right)$. This zone extends up to $V_{\mathrm{CIR}}=1$ in all the cases. The variation in $M$ against $V_{\mathrm{CIR}}$ (voltage control characteristics) for CSVS, BBCS, BSS and AZCS are presented in Fig. 6(a)-(d), respectively.

\section{Two-Zone Overmodulation Algorithm}

$M$ is controlled using $\alpha_{\text {INT }}$ in zone-I and using the notion of "hold angle" $\left(\alpha_{H}\right)$ in zone-II [6], [7]. Zone-I begins at $\alpha_{\mathrm{INT}}=$ $\left(30^{\circ}-30^{\circ} / \mathrm{N}\right)$ for AZCS and at $\alpha_{\mathrm{INT}}=30^{\circ}$ for the other strategies. It ends at $\alpha_{\mathrm{INT}}=0^{\circ}$ for BSS and at $\alpha_{\mathrm{INT}}=\left(30^{\circ} / \mathrm{N}\right)$ 


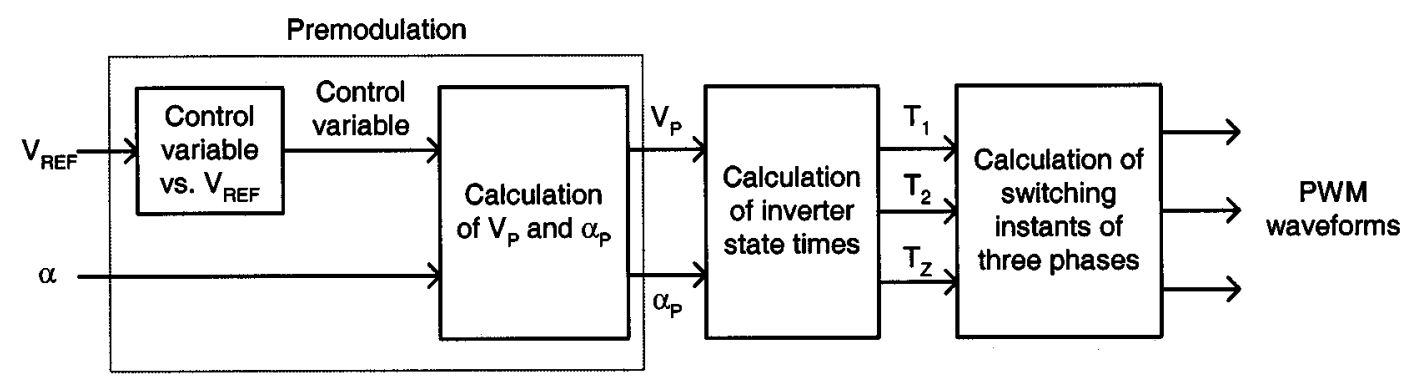

Fig. 5. Different steps in PWM calculation after sampling in every subcycle. $V_{\mathrm{REF}}, \alpha$ : Magnitude and angle, respectively, of the sample of the reference vector. $V_{P}, \alpha_{P}$ : Magnitude and angle, respectively, of the premodulated sample.

TABLE III

CAlculation of $V_{P}$ AND $\alpha_{P}$ IN DifFerent Algorithms

\begin{tabular}{|c|c|c|c|c|}
\hline gorithm & $2-\mathrm{zo}$ & lgorithm & Mod & $\mathrm{m}$ \\
\hline $\begin{array}{l}\alpha_{\mathrm{NT}}=30^{\circ}-\cos ^{-1}\left(\frac{0.866}{V_{C I R}}\right) \\
\alpha_{P}=\alpha_{I N T}, \\
\text { if } \alpha_{I N T}<\alpha<30^{\circ} \\
\quad=30^{\circ}, \text { if } \alpha=30^{\circ} \\
\quad=60^{\circ}-\alpha_{I N T}, \\
\text { if } 30^{\circ}<\alpha<\left(60^{\circ}-\alpha_{I N T}\right) \\
=\alpha, \text { otherwise } \\
V_{P}=0.866, \text { if } \alpha=30^{\circ} \\
=V_{C I R}, \text { otherwise } \ldots \text {... (3) }\end{array}$ & $\begin{aligned} \frac{\text { Zone-I }}{\alpha_{P}}=\alpha \\
V_{C I R}=\frac{0.866}{\cos \left(30^{\circ}-\alpha_{I N T}\right)} \\
V_{P}=\frac{0.866}{\cos \left(30^{\circ}-\alpha\right)} \\
\text { if } \alpha_{I N T} \leq \alpha \leq\left(60^{\circ}-\alpha_{I N T}\right) \\
\quad=V_{C I R}, \text { otherwise } \\
\ldots(4)\end{aligned}$ & $\begin{array}{l}\text { Zone-II } \\
\begin{array}{l}\alpha_{P}=\alpha \\
V_{C I R}=\frac{0.866}{\cos \left(30^{\circ}-\alpha_{I N T}\right)} \\
V_{P}=\frac{0.866}{\cos \left(30^{\circ}-\alpha\right)} \\
\text { if } \alpha_{I N T} \leq \alpha \leq\left(60^{\circ}-\alpha_{I N T}\right) \\
\quad=V_{C I R}, \text { otherwise } \\
\ldots(5)\end{array}\end{array}$ & $\begin{array}{l}\frac{\text { Zone-I }}{\alpha_{P}=\alpha} \\
V_{P(M A X)}=\frac{0.866}{\cos \left(30^{\circ}-\alpha\right)} \\
V_{P}=V_{P(M A X)} \\
\text { if } V_{C I R}>V_{P(M A X)} \\
\quad=V_{C I R}, \text { otherwise } \\
\ldots(6)\end{array}$ & $\begin{array}{l}\text { Zone-II } \\
\begin{array}{c}\alpha_{P}=0^{\circ}, \text { if } 0^{\circ} \leq \alpha<\alpha_{H} \\
=30^{\circ} * \frac{\alpha-\alpha_{H}}{30^{\circ}-\alpha_{H}}, \\
\text { if } \alpha_{H} \leq \alpha \leq\left(60^{\circ}-\alpha_{H}\right) \\
=60^{\circ}, \text { otherwise } \\
V_{P}=\frac{0.866}{\cos \left(30^{\circ}-\alpha_{P}\right)} \\
\ldots \text { (7) }\end{array}\end{array}$ \\
\hline
\end{tabular}

a
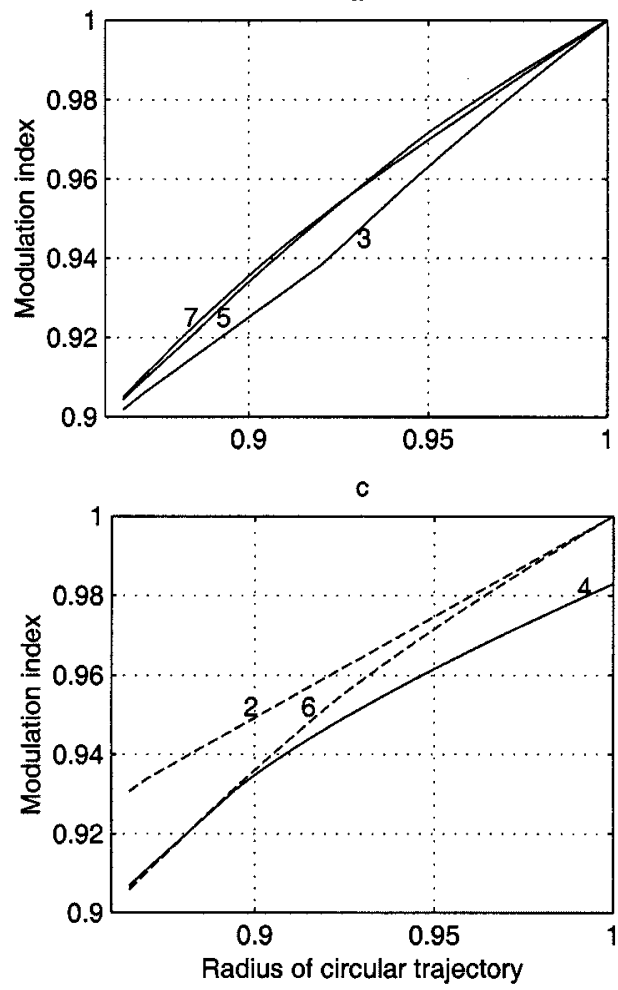

b

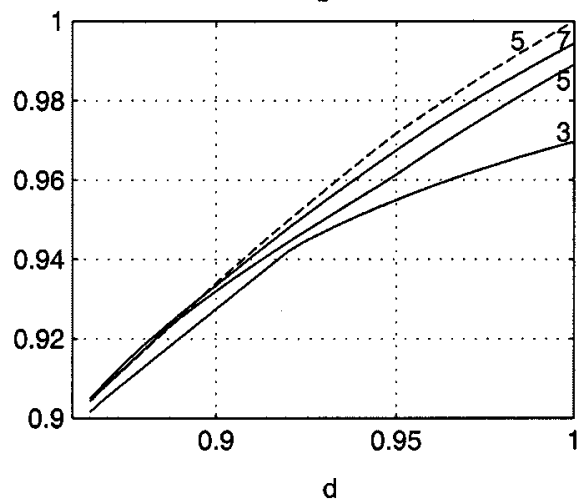

d

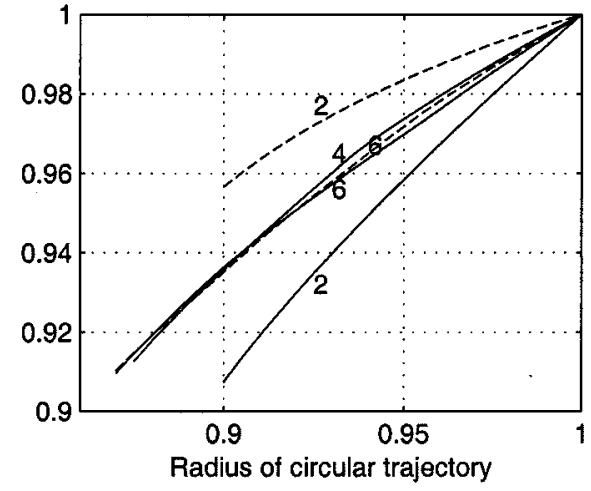

Fig. 6. Voltage control using one-zone overmodulation algorithm: (a) CSVS, (b) BBCS, (c) BSS, and (d) AZCS. (b)-(d) Solid line $-60^{\circ}$ clamping, dashed line $-30^{\circ}$ clamping. 

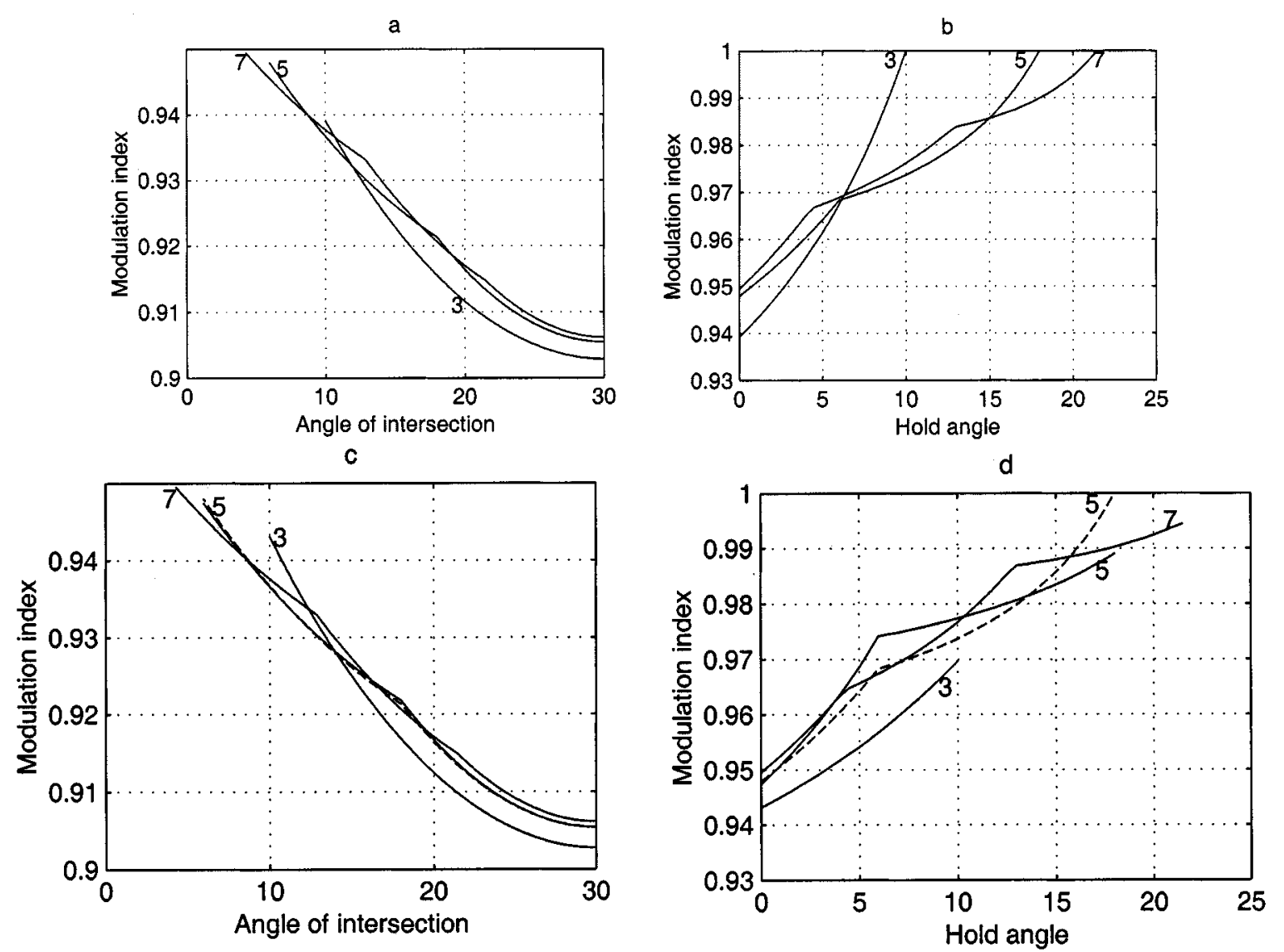

Fig. 7. Voltage control using two-zone overmodulation algorithm-CSVS and BBCS: (a) CSVS, zone-I, (b) CSVS, zone-II, (c) BBCS, zone-I, and (d) BBCS, zone-II. (c)-(d) Solid line $-60^{\circ}$ clamping, dashed line $-30^{\circ}$ clamping.
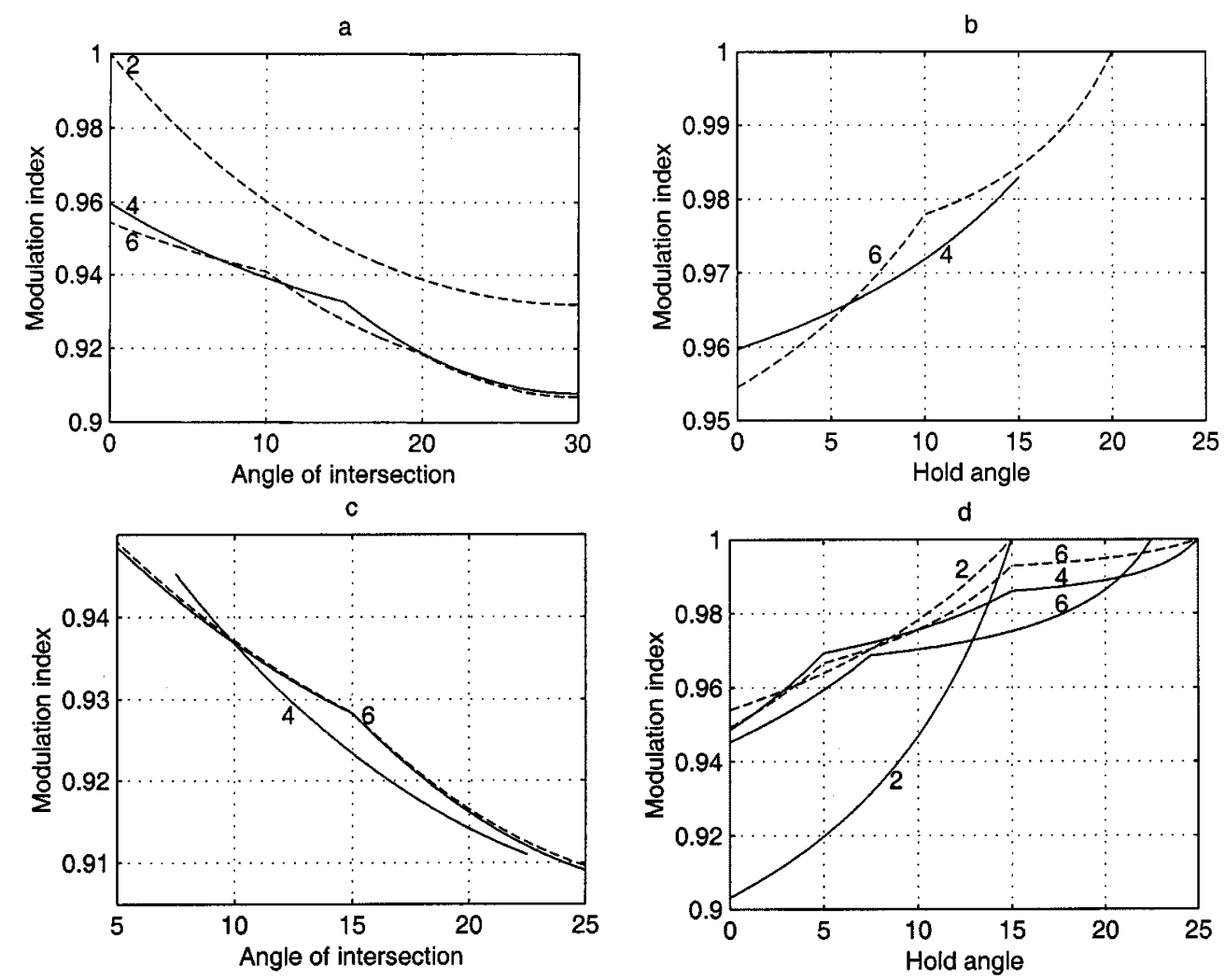

Fig. 8. Voltage control using two-zone overmodulation algorithm—BSS and AZCS: (a) BSS, zone-I, (b) BSS, zone-II, (c) AZCS, zone-I, and (d) AZCS, zone-II. Solid line $-60^{\circ}$ clamping, dashed line $-30^{\circ}$ clamping. 

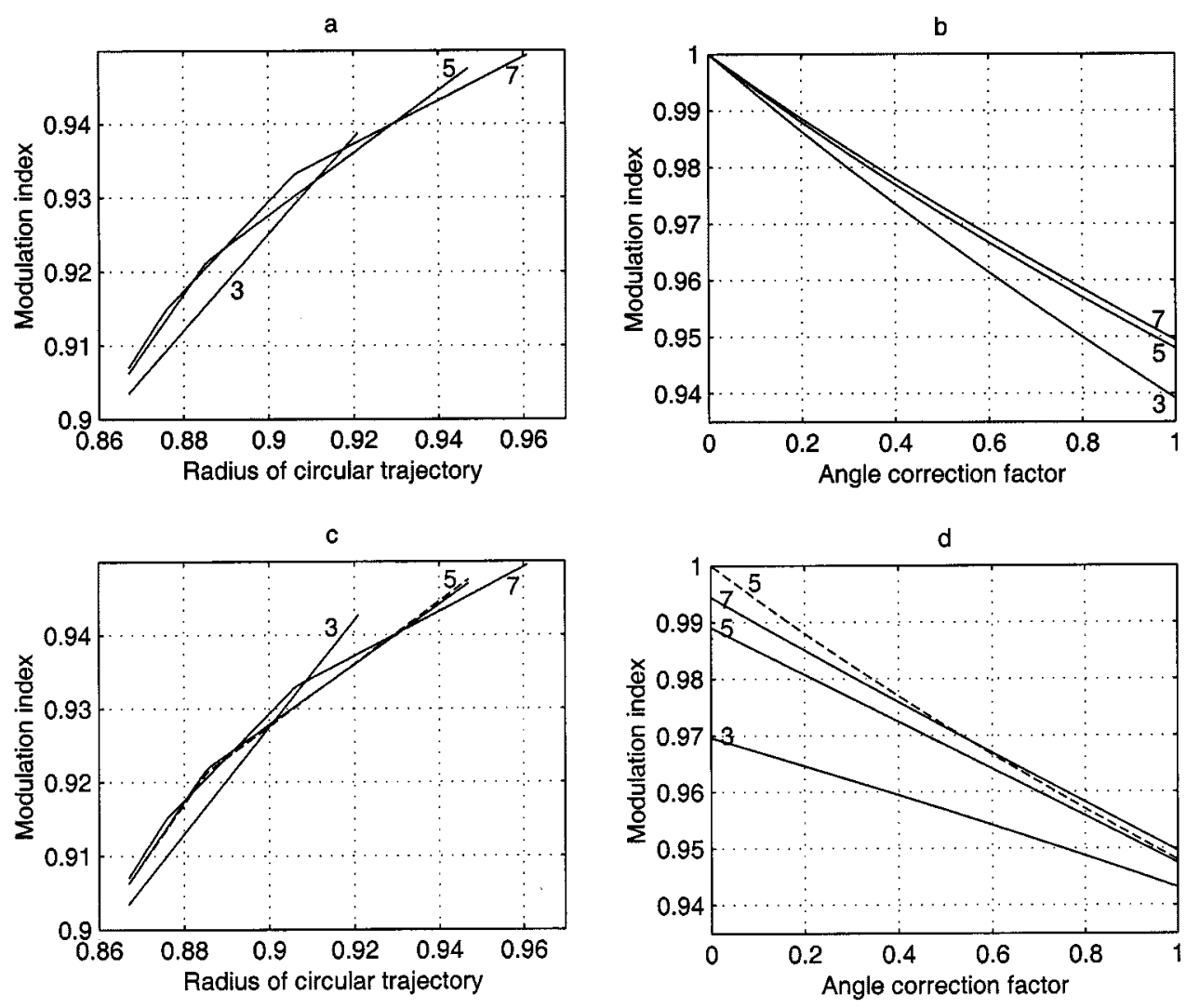

Fig. 9. Voltage control using modified two-zone overmodulation algorithm-CSVS and BBCS: (a) CSVS, zone-I, (b) CSVS, zone-II, (c) BBCS, zone-I, and (d) BBCS, zone-II. (c)-(d) Solid line $-60^{\circ}$ clamping, dashed line $-30^{\circ}$ clamping.
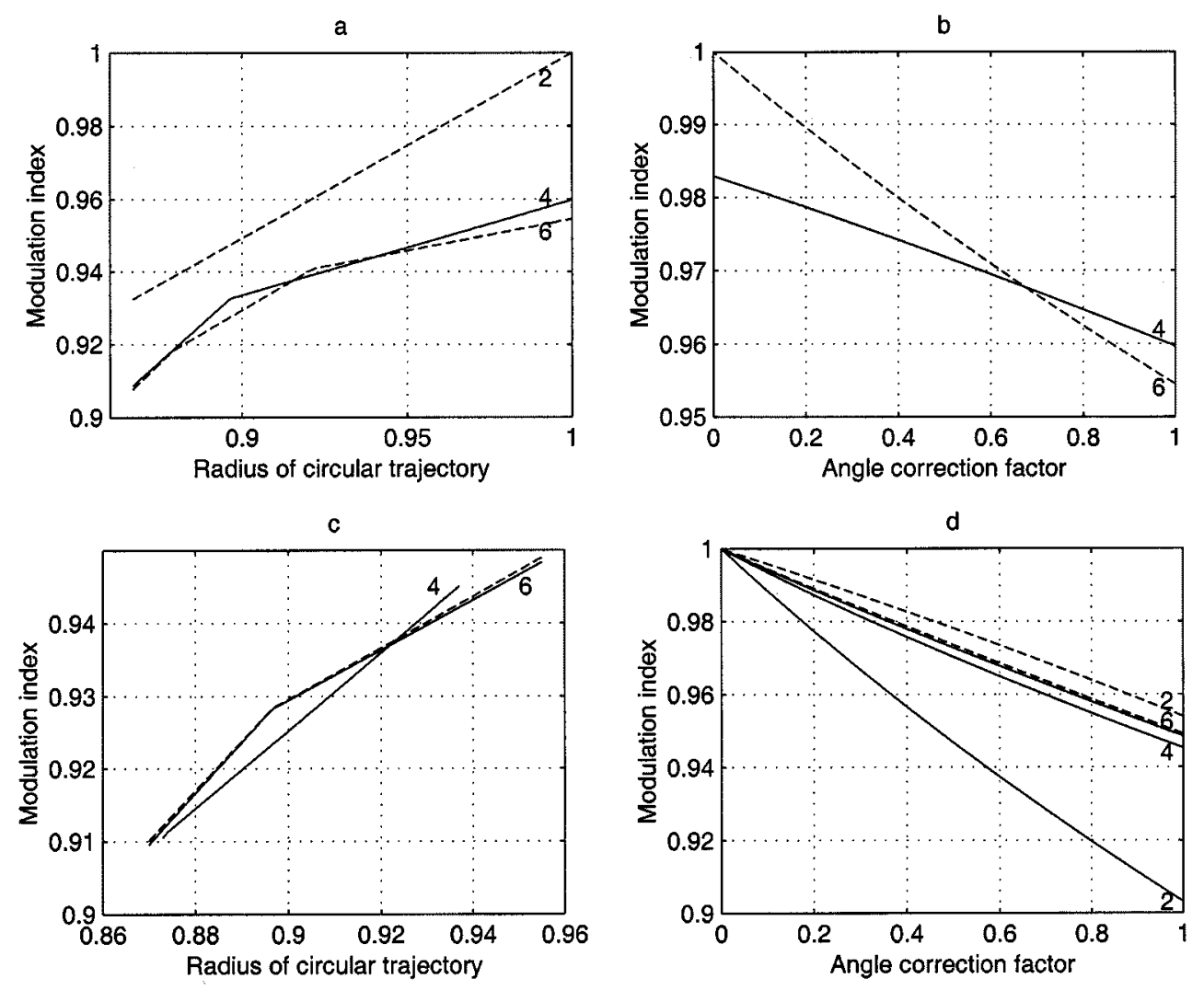

Fig. 10. Voltage control using modified two-zone overmodulation algorithm-BSS and AZCS: (a) BSS, zone-I, (b) BSS, zone-II, (c) AZCS, zone-I, and (d) AZCS, zone-II. Solid line $-60^{\circ}$ clamping, dashed line $-30^{\circ}$ clamping. 
TABLE IV

MAXIMUM MODULATION INDEX $\left(M_{\mathrm{MAX}}\right)$

\begin{tabular}{c|c|c|c|c|c|c}
\hline Strategy & $\mathrm{N}$ & $\begin{array}{c}\text { Type of } \\
\text { clamping }\end{array}$ & Positions of samples $(\alpha)$ & $\begin{array}{c}\text { Magnitudes and positions of premodulated } \\
\text { samples at } \mathrm{M}_{\text {MAX }}\end{array}$ & $\begin{array}{c}\text { Sequences used } \\
\text { at } \mathrm{M}_{\text {MAX }}\end{array}$ & M $_{\text {MAX }}$ \\
\hline CSVS & 3 & - & $10^{\circ}, 30^{\circ}, 50^{\circ}$ & $1 \angle 0^{\circ}, 0.866 \angle 30^{\circ}, 1 \angle 60^{\circ}$ & $1,12,2$ & 1 \\
\hline BBCS & 5 & $60^{\circ}$ & $6^{\circ}, 18^{\circ}, 30^{\circ}, 42^{\circ}, 54^{\circ}$ & $1 \angle 0^{\circ}, 1 \angle 0^{\circ}, 0.866 \angle 30^{\circ}, 1 \angle 60^{\circ}, 1 \angle 60^{\circ}$ & $1,1,21,2,2$ & 0.989 \\
\hline BBCS & 5 & $30^{\circ}$ & $6^{\circ}, 18^{\circ}, 30^{\circ}, 42^{\circ}, 54^{\circ}$ & $1 \angle 0^{\circ}, 1 \angle 0^{\circ}, 0.866 \angle 30^{\circ}, 1 \angle 60^{\circ}, 1 \angle 60^{\circ}$ & $1,1,12,2,2$ & 1 \\
\hline BSS & 4 & $60^{\circ}$ & $0^{\circ}, 15^{\circ}, 30^{\circ}, 45^{\circ}$ & $1 \angle 0^{\circ}, 1 \angle 0^{\circ}, 0.866 \angle 30^{\circ}, 1 \angle 60^{\circ}$ & $1,1,21,2$ & 0.983 \\
\hline BSS & 6 & $30^{\circ}$ & $0^{\circ}, 10^{\circ}, 20^{\circ}, 30^{\circ}, 40^{\circ}, 50^{\circ}$ & $1 \angle 0^{\circ}, 1 \angle 0^{\circ}, 1 \angle 0^{\circ}, 0.866 \angle 30^{\circ}, 1 \angle 60^{\circ}, 1 \angle 60^{\circ}$ & $1,1,1,12,2,2$ & 1 \\
\hline AZCS & 4 & $60^{\circ}$ & $7.5^{\circ}, 22.5^{\circ}, 37.5^{\circ}, 42.5^{\circ}$ & $1 \angle 0^{\circ}, 1 \angle 0^{\circ}, 1 \angle 60^{\circ}, 1 \angle 60^{\circ}$ & $1,1,2,2$ & 1 \\
\hline AZCS & 6 & $30^{\circ}$ & $5^{\circ}, 15^{\circ}, 25^{\circ}, 35^{\circ}, 45^{\circ}, 55^{\circ}$ & $1 \angle 0^{\circ}, 1 \angle 0^{\circ}, 1 \angle 0^{\circ}, 1 \angle 60^{\circ}, 1 \angle 60^{\circ}, 1 \angle 60^{\circ}$ & $1,1,1,2,2,2$ & 1 \\
\hline
\end{tabular}

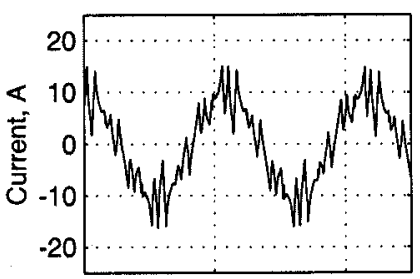

b

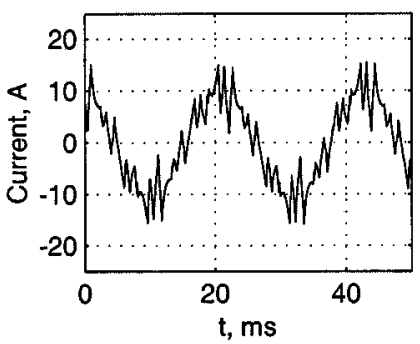

c

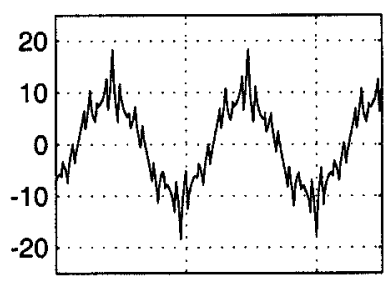

d

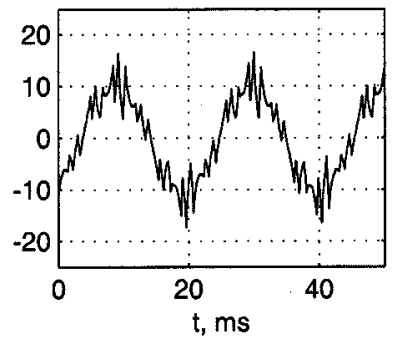

$\theta$
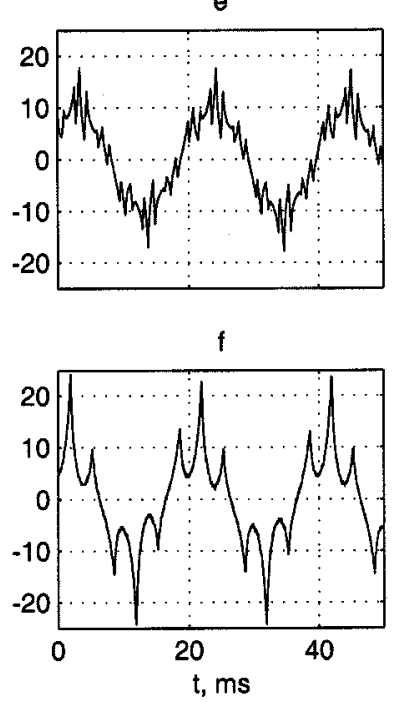

Fig. 11. Experimental no-load current waveforms for AZCS with $N=4$ : (a) $M=0.92$, one-zone algorithm, (b) $M=0.92$, two-zone and modified two-zone algorithms, (c) $M=0.96$, one-zone algorithm, (d) $M=0.96$, two-zone algorithm, (e) $M=0.96$, modified two-zone algorithm, and (f) six-step no-load current waveform $\left(M_{\mathrm{MAX}}=1\right)$ common to CSVS, AZCS, BBCS with $30^{\circ}$ clamping, and BSS with $30^{\circ}$ clamping corresponding to all three algorithms (see Fig. $14(\mathrm{c})$ for distortion factors corresponding to above waveforms).

for other strategies. Zone-II begins at $\alpha_{H}=0^{\circ}$ for all strategies. It ends at $\alpha_{H}=\left(30^{\circ}-30^{\circ} / \mathrm{N}\right)$ for AZCS and at $\alpha_{H}=$ $\left(30^{\circ}-60^{\circ} / \mathrm{N}\right)$ for other strategies. The voltage control characteristics in the two zones corresponding to the four strategies are presented in Figs. 7 and 8.

\section{E. Modified Two-Zone Overmodulation Algorithm}

In zone-I, $M$ is controlled using $V_{\mathrm{CIR}}$. In zone-II, the average vectors generated are shifted closer to the nearest sector boundary using a fraction termed as "angle correction factor" ( $K_{\mathrm{ANG}}$ ) to increase $M$ [8]. The angle of the sample, measured from its nearest sector boundary, is multiplied by this fraction $K_{\text {ANG }}$ to get the position of the premodulated sample. $V_{P}$ is the maximum length of average vector possible at $\alpha_{P}$. The equations for calculating $V_{P}$ and $\alpha_{P}$ are shown in Table III. Zone-I begins at $V_{\mathrm{CIR}}=0.866 / \cos \left(30^{\circ} / \mathrm{N}\right)$ for AZCS and at $V_{\mathrm{CIR}}=0.866$ for other strategies. It ends at $V_{\mathrm{CIR}}=1$ for BSS and at $V_{\mathrm{CIR}}=0.866 / \cos \left(30^{\circ}-30^{\circ} / \mathrm{N}\right)$ for other strategies. The range of $K_{\mathrm{ANG}}$ in zone-II is from 1 to 0 for all strategies. The voltage control characteristics are presented in Figs. 9 and 10.

\section{F. Maximum Modulation Index ( $\left.M_{\mathrm{MAX}}\right)$}

The magnitudes and positions of the premodulated samples, and the state transitions in sector I at the maximum modulation index are tabulated in Table IV for representative example cases. These hold good for all three overmodulation algorithms. If a PWM strategy has no sample at $\alpha=30^{\circ}$ or if such a sample uses the sequence $\mathbf{0 1 2 7}$ during linear modulation, then there is only one state transition in every sector (from $\mathbf{1}$ to $\mathbf{2}$ in sector I). This is the six-step mode. Thus, $M_{\mathrm{MAX}}=1$ for CSVS, AZCS, BBCS with $30^{\circ}$ clamping and BSS with $30^{\circ}$ clamping. If a PWM strategy has a sample at $\alpha=30^{\circ}$, which uses the sequence $\mathbf{7 2 1 0}$ during linear modulation, then there are 3 state transitions in every sector (1-2-1-2 in sector I)—one each at the start, middle and end of the middle subcycle. Here $M_{\text {MAX }}=\left[2 \cos \left(30^{\circ} / \mathrm{N}\right)-1\right]$. This applies to BBCS with $60^{\circ}$ clamping and BSS with $60^{\circ}$ clamping. $M_{\mathrm{MAX}}$ is independent of the overmodulation algorithm used. 


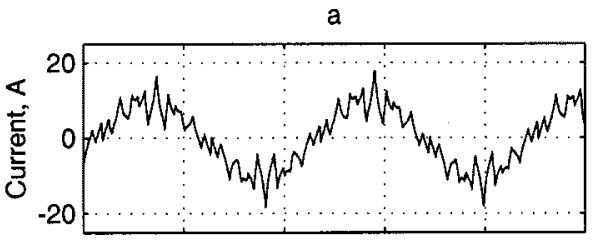

b
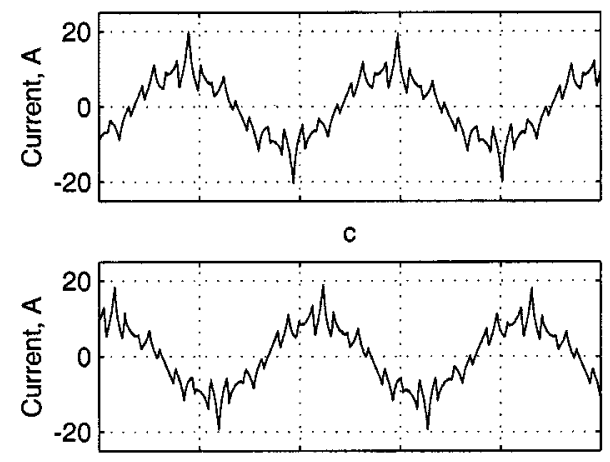

d

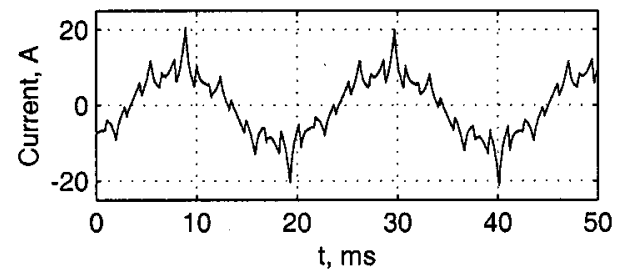

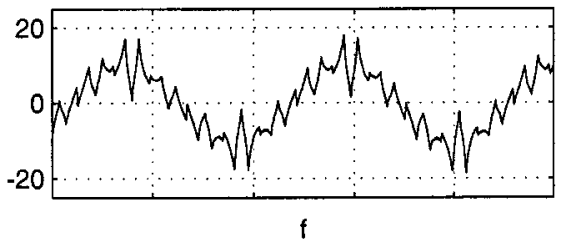

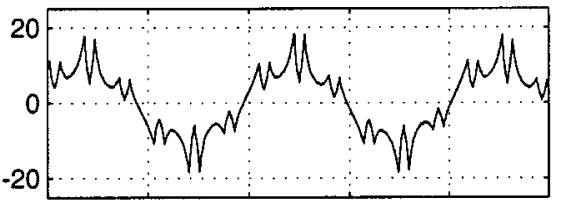

g

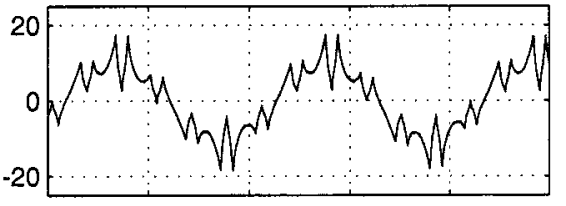

$\mathrm{h}$

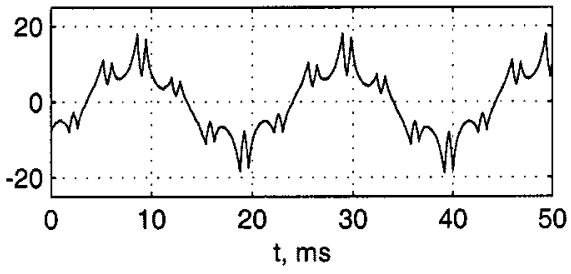

Fig. 12. Experimental no-load current waveforms for (a)-(d) BBCS, $N=5,30^{\circ}$ clamping and (e)-(h) BSS, $N=4:$ (a) $M=0.92$, all three algorithms, (b) $M=0.96$, one-zone algorithm, (c) $M=0.96$, two-zone algorithm, (d) $M=0.96$, modified two-zone algorithm, (e) $M=0.92$, all three algorithms, (f) $M=0.96$, one-zone algorithm, (g) $M=0.96$, two-zone and modified two-zone algorithms, and (h) $M=M_{\mathrm{MAX}}=0.983$, all three algorithms (see Fig. 14(b) and (d) for distortion factors corresponding to above waveforms).

\section{G. Maintenance of Proportionality}

Given the overmodulation algorithm, zone of modulation, PWM strategy, $N$, and type of clamping (if applicable), the appropriate voltage control curve ( $M$ versus control variable) and (2) are used to arrive at the control variable versus $V_{\text {REF }}$ curve. This curve is stored as a look-up table or polynomial/linear approximation, and used during premodulation to determine the value of the control variable corresponding to the given $V_{\mathrm{REF}}$ (see Fig. 5). This ensures proportionality between $V_{\mathrm{REF}}$ and $M$ as per (2) during overmodulation.

\section{H. Preservation of Waveform Symmetries}

Given samples of equal magnitude $V_{\mathrm{REF}}$ and positions as shown in Table I, all three overmodulation algorithms ensure that magnitudes and positions of the premodulated samples are symmetrical about the centre of the sector, and that the sample at $\alpha=30^{\circ}$, if any, has a corresponding premodulated sample at $\alpha_{P}=30^{\circ}$. This ensures that the conditions for waveform symmetries [8], [10] continue to be satisfied during overmodulation.

Though all the premodulated samples are supposed to be in the spatial zones where the circle is within the hexagon in the one-zone approach to overmodulation, there is one premodulated sample outside this zone at $\alpha_{P}=30^{\circ}$ if there is a corresponding sample at $\alpha=30^{\circ}$. This is necessary to maintain the waveform symmetries.

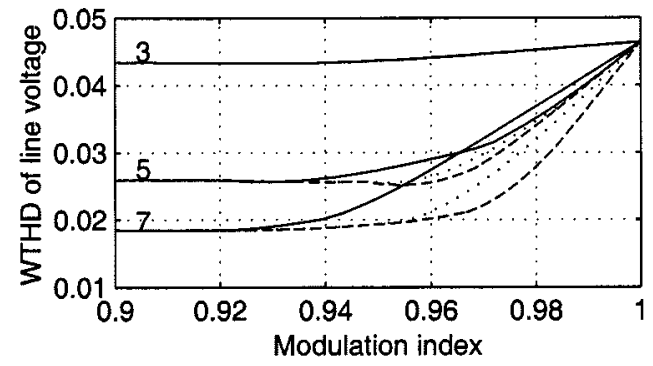

Fig. 13. Harmonic distortion due to CSVS with three overmodulation algorithms. Solid line: one-zone algorithm, dashed line: two-zone algorithm, dotted line: modified two-zone algorithm.

\section{RESULTS AND DISCUSSION}

Results pertaining to the operation of the four low switching frequency PWM strategies in the overmodulation zone are presented and discussed. The overmodulation algorithms are compared and contrasted in terms of fundamental voltage control and waveform quality. The differences in overmodulation at low and high switching frequencies are brought out.

\section{A. Voltage Control}

At high switching frequencies, overmodulation zone begins at $M=0.907$ and ends at $M_{\mathrm{MAX}}=1$ [5]-[8]. With two-zone approach, zone-I ends and zone-II begins at $M=0.952$ [6]-[8]. These boundaries of zones of modulation are practically independent of sampling frequency and sequences used. 


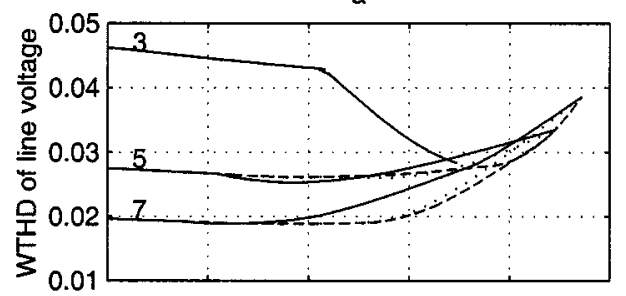

b
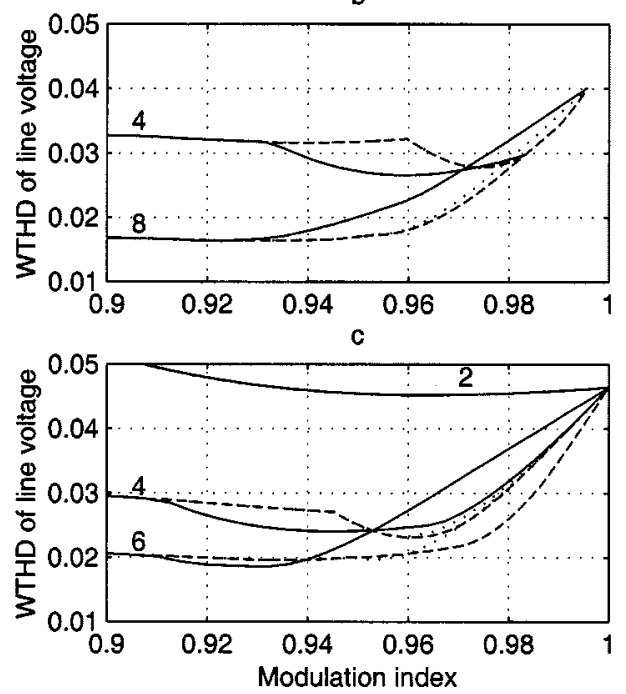

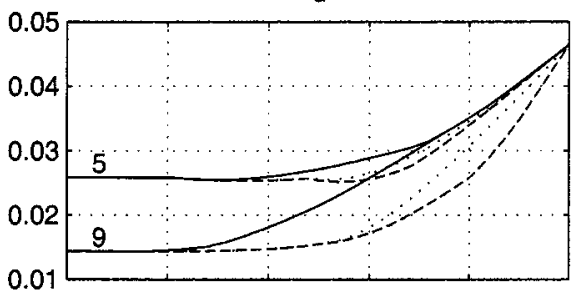

$\Theta$

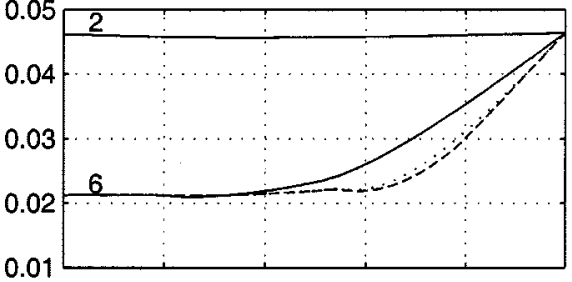

f

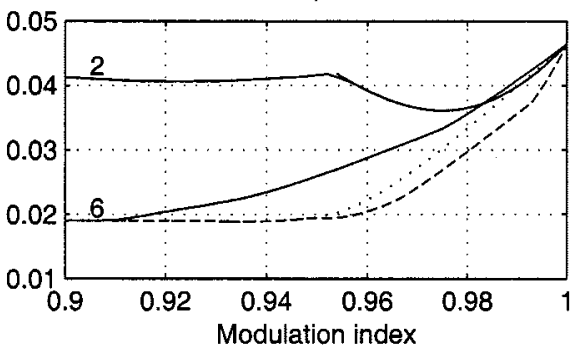

Fig. 14. Harmonic distortion due to bus clamping strategies with three overmodulation algorithms: (a) BBCS, $60^{\circ}$ clamping, (b) BSS, $60^{\circ}$ clamping, (c) AZCS, $60^{\circ}$ clamping, (d) BBCS, $30^{\circ}$ clamping, (e) BSS, $30^{\circ}$ clamping, and (f) AZCS, $30^{\circ}$ clamping. Solid line: one-zone algorithm, dashed line: two-zone algorithm, dotted line: modified two-zone algorithm.

At low switching frequencies, these boundaries vary with PWM strategy, $N$ and type of clamping (if applicable), but are independent of the overmodulation algorithm employed (see Figs. 6-10).

Except zone-II characteristics with modified two-zone algorithm [Figs. 9(b) and (d) and 10(b) and (d)], other voltage control curves, in general, have multiple sections, separated by points at which the slope of the curve is discontinuous. These points correspond to the positions of samples $(\alpha)$ for the given strategy and $N$ (see Table I). There is no such discontinuity in the slope at high switching frequencies [5]-[8].

Given identical sample positions, $N$ and an overmodulation algorithm, the voltage control curves differ with the PWM strategy or type of clamping (if applicable). That is, for the same set of average vectors generated, the fundamental voltages differ with sequences used. Also, given an overmodulation algorithm and a PWM strategy, the voltage control characteristics vary with $N$. Thus, at low switching frequencies, both sequences and sampling frequency influence the fundamental voltage significantly unlike at high switching frequencies.

\section{B. Experimental Current Waveforms}

The PWM strategies, with extended zones of operation, are implemented on an INTEL 80C196KB micro-controller. The prototype is a $200 \mathrm{~V}, 3 \mathrm{~kW}, 50 \mathrm{~Hz}$ constant V/F induction motor drive fed from a 5 kVA IGBT-based inverter.
The measured no-load current waveforms are presented for AZCS with $N=4$, BBCS with $N=5$ and $30^{\circ}$ clamping, and BSS with $N=4$ in Figs. 11(a)-(f) and 12(a)-(h), respectively. Waveforms at $M=0.92,0.96$, and $M_{\mathrm{MAX}}$ are shown for all three algorithms. $M_{\mathrm{MAX}}=1$ for AZCS and BBCS with $30^{\circ}$ clamping. The six-step no-load current waveform is shown in Fig. 11(f). The no-load current waveforms corresponding to BSS with $N=4$ [Fig. 12(e)-(h)] have a dip near the peak of the fundamental in the whole range of modulation up to $M_{\mathrm{MAX}}$. This is characteristic of BBCS with $60^{\circ}$ clamping and BSS with $60^{\circ}$ clamping, which do not operate up to the six-step mode. The waveform at $M_{\mathrm{MAX}}=0.983$ for BSS with $N=4$ is shown in Fig. 12(h).

\section{Waveform Quality}

The weighted total harmonic distortion factor ( $\left.V_{\text {WTHD }}\right)$ of the line voltage waveform is a suitable performance measure of the PWM strategies, and is independent of the motor parameters [10], [11]. A comparison of the $V_{\text {WTHD }}$ versus $M$ characteristics with different overmodulation algorithms is presented for CSVS in Fig. 13. A similar comparison for the bus clamping strategies is presented in Fig. 14.

The harmonic distortion corresponding to the no-load current waveforms in Fig. 11(a)-(f) (AZCS, $N=4$ ), Fig. 12(a)-(d) (BBCS, $N=5,30^{\circ}$ clamping), and Fig. 12(e)-(h) (BSS, $N=$ 4) can be seen from their respective curves in Fig. 14(c), (d), 
and (b), respectively. Two or more overmodulation algorithms lead to identical waveforms [see Figs. 11(b), 12(a), (e), and $(\mathrm{g})]$ in certain portions of the overmodulation zone, resulting in equal distortion [see Fig. 14(b)-(d)]. Even in other regions, the distortion factors are not significantly different at such low $P_{\mathrm{NOM}}$. The waveforms at a given $M$ appear "almost" identical [see Fig. 11(a)-(e); Fig. 12(b)-(d); and Fig. 12(f) and (g)]. In fact, at the lowest possible $P_{\mathrm{NOM}}$ with any PWM strategy, all three algorithms result in identical PWM waveforms, and hence, equal harmonic distortion in the whole overmodulation zone as shown in Figs. 13 and 14. The distortion factors corresponding to different algorithms are significantly different only at higher $P_{\text {NOM. }}$.

Comparing the $V_{\text {WTHD }}$ curves corresponding to CSVS with $N=3$ in Fig. 13, BSS with $N=4$ in Fig. 14(b) and AZCS with $N=4$ in Fig. 14(c) (all having $P_{\mathrm{NOM}}=9$ ), it can be seen that bus clamping strategies result in lesser harmonic distortion over CSVS in the overmodulation zone with any given overmodulation algorithm used. Similar is the observation in case of CSVS with $N=5$ or $P_{\mathrm{NOM}}=15$ (see Fig. 13), BSS with $N=6$ or $P_{\mathrm{NOM}}=13$ [see Fig. 14(e)] and AZCS with $N=6$ or $P_{\text {NOM }}=13$ [see Fig. 14(f)]. Thus, with any given overmodulation algorithm, the bus clamping strategies perform better than CSVS.

\section{CONCLUSION}

Any of the three existing overmodulation algorithms can be used to extend the operation of the space vector-based synchronized PWM strategies into the overmodulation zone. It is shown that the symmetries in the PWM waveforms generated can be maintained in the overmodulation zone as well.

Given a synchronized PWM strategy and an overmodulation algorithm, the voltage control characteristics vary with the nominal pulse number and type of clamping (if applicable), leading to a family of curves. The inverse of the appropriate voltage control curve is used during premodulation to maintain the modulator gain constant.

The voltage control characteristics corresponding to onezone and two-zone algorithms, when applied to the above low switching frequency PWM strategies, are found to be more complex than the characteristics at high switching frequencies. When applied to the above synchronized PWM strategies, the characteristics corresponding to both one-zone and two-zone algorithms have multiple nonlinear sections. The discontinuities in the slope of the characteristics are more pronounced with the two-zone algorithm, especially in zone-II.

Unlike at high switching frequencies wherein the one-zone algorithm always results in a higher harmonic distortion than the two-zone algorithm, it is shown that the former leads to lesser distortion than the latter in the initial or middle portion of the overmodulation zone in $60^{\circ}$ clamping schemes with nominal pulse numbers in the range of nine to 13 . Otherwise, the one-zone algorithm always results in an equal or higher distortion than the two-zone algorithm.

In general, with modified two-zone algorithm, the distortion is substantially less than that with the one-zone algorithm, and is higher than that with the two-zone algorithm only in zone-II. But this algorithm has the advantage of simpler voltage control characteristics over the two-zone algorithm. The characteristics are piecewise linear in zone-I, and are "almost" linear in zone-II.

With any given overmodulation algorithm, it is shown that the bus clamping PWM strategies result in lesser harmonic distortion than CSVS in the overmodulation zone. The superior waveform quality and high dc bus utilization make these strategies useful in the high speed ranges of high power drives.

\section{REFERENCES}

[1] A. M. Hava, T. A. Lipo, and R. J. Kerkman, "Carrier-based PWM-VSI overmodulation strategies: Analysis, comparison and design," IEEE Trans. Power Electron., vol. 13, pp. 674-689, July 1998.

[2] V. Kaura, "A new method to linearize any triangle-comparison-based PWM by reshaping the modulation command," IEEE Trans. Ind. Applicat., vol. 33, pp. 1254-1259, Sept./Oct. 1997.

[3] A. Bakshai, G. Joos, P. Jain, and H. Jin, "Incorporating the over-modulation range in space vector pattern generators using a classification algorithm in PWM inverters," IEEE Trans. Power Electron., vol. 15, pp. 83-91, Jan. 2000.

[4] J. Mahlein, O. Simon, and M. Braun, "A matrix converter with space vector control enabling overmodulation," in Proc. EPE'99 Conf., Lausanne, Switzerland, 1999.

[5] S. Bolognani and M. Zigliotto, "Novel digital continuous control of SVM inverters in the overmodulation range," IEEE Trans. Ind. Applicat., vol. 33, pp. 525-530, Mar./Apr. 1997.

[6] J. Holtz, W. Lotzkat, and A. Khambadkone, "On continuous control of PWM inverters in the overmodulation range including the six-step mode," IEEE Trans. Power Electron., vol. 8, pp. 546-553, July 1993.

[7] D.-C. Lee and G.-M. Lee, "A novel overmodulation technique for space-vector PWM inverters," IEEE Trans. Power Electron., vol. 13, pp. 1144-1151, Nov. 1998.

[8] G. Narayanan, "Synchronised pulsewidth modulation strategies based on space vector approach for induction motor drives," Ph.D. thesis, Indian Inst. Sci., Bangalore, India, 1999.

[9] G. Narayanan and V. T. Ranganathan, "Triangle-comparison approach and space vector approach to real-time PWM strategies," J. Indian Inst. Sci., vol. 80, pp. 409-427, Sep.-Oct. 2000.

[10] —, "Synchronised PWM strategies based on space vector approach Part 1: Principles of waveform generation," Proc. Inst. Elect. Eng. B, vol. 146, pp. 267-275, May 1999.

[11] _ - "Synchronised PWM strategies based on space vector approach Part 2: Performance assessment and application to V/f drives," Proc. Inst. Elect. Eng. B, vol. 146, pp. 276-281, May 1999.

[12] H. Stemmler, "High-power industrial drives," Proc. IEEE, vol. 82, pp. 1266-1286, Aug. 1994.

[13] P. G. Handley and J. T. Boys, "Practical real-time PWM modulators-An assessment," Proc. Inst. Elect. Eng. B, vol. 139, no. 2, pp. 96-102, 1992.

[14] J. Holtz, "Pulsewidth modulation for electronic power conversion," Proc. IEEE, vol. 82, pp. 1194-1214, Aug. 1994.

[15] D. G. Holmes, "The significance of zero space vector placement for carrier-based PWM schemes," IEEE Trans. Ind. Applicat., vol. 32, pp. 1122-1129, Sept./Oct. 1996.

[16] V. Blasko, "Analysis of a hybrid PWM based on modified space-vector and triangle-comparison methods," IEEE Trans. Ind. Applicat., vol. 33, pp. 756-764, May/June 1997.

[17] A. M. Hava, R. J. Kerkman, and T. A. Lipo, "Simple analytical and graphical methods for carrier-based PWM-VSI drives," IEEE Trans. Power Electron., vol. 14, pp. 49-61, Jan. 1999.

[18] D.-W. Chung, J.-S. Kim, and S.-K. Sul, "Unified voltage modulation technique for real-time three-phase power conversion," IEEE Trans. Ind. Applicat., vol. 34, pp. 374-380, Mar./Apr. 1998.

[19] J.-H. Youm and B.-H. Kwon, "An effective software implementation of the space-vector modulation," IEEE Trans. Ind. Electron., vol. 46, pp. 866-868, Aug. 1999. 


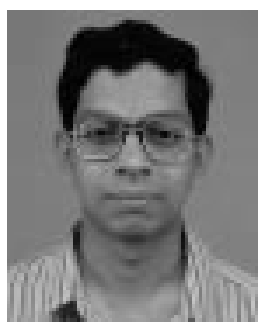

G. Narayanan (S'99-M'01) received the B.E. degree from Anna University, Madras, India, in 1992, the M.Tech. degree from the Indian Institute of Technology, Kharagpur, in 1994, and the Ph.D. degree from the Indian Institute of Science, Bangalore, in 2000 .

$\mathrm{He}$ is currently a Research Associate in the Department of Electrical Engineering, Indian Institute of Science, Bangalore. His research interests include ac drives, pulsewidth modulation, multilevel inverters, and protection of power devices.

Dr. Narayanan received the Innovative Student Project Award from the Indian National Academy of Engineering in 2000.

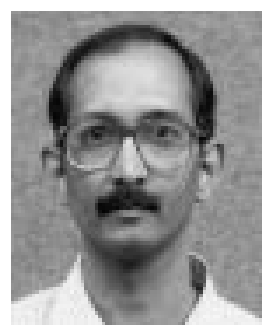

V. T. Ranganathan (SM'84) received the B.E. and M.E. degrees in electrical engineering from the Indian Institute of Science (I.I.Sc.), Bangalore, and the Ph.D. degree from Concordia University, Montreal, QC, Canada.

He joined the Electrical Engineering Department, I.I.Sc., in 1984 and is currently a Professor. His research interests are in the area of power electronics and motor drives. He has published several papers in the areas of vector control of ac drives, PWM techniques, split phase induction motor drives, and rotor side control of slip ring induction motors. He is also a consultant to industry in the above areas and has participated in a number of projects.

Dr. Ranganathan received the Prize Paper Award of the IEEE-IAS Static Power Converter Committee and the Tata Rao Prize of the Institution of Engineers, India. He is a Fellow of the Institution of Engineers, India. 